\title{
Immune-Related Adverse Events: Pneumonitis
}

\author{
Linda Zhong, Mehmet Altan, Vickie R. Shannon, \\ and Ajay Sheshadri
}

\begin{abstract}
Checkpoint inhibitors are part of the family of immunotherapies and are increasingly being used in a wide variety of cancers. Immunerelated adverse events pose a major challenge in the treatment of cancer patients. Pneumonitis is a rare immune-related adverse event that presents in distinct patterns. The goal of this chapter is to instruct readers on the incidence and clinical manifestations of pneumonitis and to offer guidance in the evaluation and treatment of patients with pneumonitis.
\end{abstract}

\section{Keywords}

Checkpoint inhibitors $\cdot$ Immune-related adverse event · Pneumonitis - Thoracic imaging · Organizing pneumonia .

\section{Zhong}

Department of Investigational Cancer Therapeutics, The University of Texas MD Anderson Cancer Center, Houston, TX, USA

M. Altan

Department of Thoracic/Head and Neck Medical Oncology, The University of Texas MD Anderson Cancer Center, Houston, TX, USA

V. R. Shannon · A. Sheshadri $(\bowtie)$

Department of Pulmonary Medicine, The University of Texas MD Anderson Cancer Center, Houston, TX, USA

e-mail: asheshadri@mdanderson.org
Nonspecific interstitial pneumonia . Hypersensitivity pneumonitis - Diffuse alveolar damage

\section{Introduction}

The prevalence of cancer is rising in parallel with increasing life expectancy [1]. Recurrent and refractory cancers pose major therapeutic challenges for clinicians, and new strategies are necessary to counter the evolving landscape of cancer [2]. Immunotherapy is one such strategy where the immune system can be weaponized against cancers to induce a potentially durable reduction in tumor burden [3-5]. Common targets of immunotherapy agents include the programmed cell death protein 1 (PD-1) pathway and the cytotoxic T-lymphocyte-associated protein-4 pathways (CTLA-4), which we discuss in detail below [6]. Tumor cells can suppress the natural antitumor activity of T-cells through several mechanisms, including expression of PD-L1 (a ligand for PD-1) and CTLA-4 [7]. Inhibitors of the PD-1 and CTLA-4 pathways boost antitumor immune responses by preventing homeostatic downregulation of T-lymphocyte activity, which normally occurs during chronic infection to prevent excessive tissue injury [8, 9]. However, a reinvigorated immune system may lead to disturbances in 
normal immune self-tolerance and, as a result, may induce off-target immune-related adverse events (irAEs), which may affect numerous organs. In this chapter, we focus on pulmonary irAEs that occur after immunotherapeutic agents.

\section{Inhibition of T-Lymphocyte Function by the PD-1 and CTLA-4 Pathways}

PD-1 is a monomeric transmembrane protein in the immunoglobulin superfamily that is found on the surface of macrophages and $\mathrm{T}$ - and B-lymphocytes [10-12]. PD-1 is primarily expressed in mature T-cells and appears within $24 \mathrm{~h}$ of T-cell activation as a mechanism to regulate T-cell activity to prevent injury to healthy tissue [13]. PD-1 binds primarily to two ligands, PD-L1 and PD-L2. PD-L1 is broadly expressed by hematopoietic cell lineages and various epithelial and endothelial cells, while PD-L2 is expressed primarily by dendritic cells and B-lymphocytes [10]. Several inflammatory cytokines can induce PD-L1 expression on the surface of lymphocytes and on nonimmune cells [11]. The interaction of PD-1 with its ligands causes the recruitment of phosphatase Src homology protein 2 (SHP2), which leads to subsequent inactivation of the PI3K/AKT signaling $[14,15]$. In T-lymphocytes, activation of the PD-1 pathway blocks proliferation, impairs inflammation, and decreases survival [16]. Binding of PD-1 to PD-L2 decreases T-lymphocyte cytokine production, but does not inhibit proliferation [17]. Furthermore, activation of the PD-1 pathway induces the differentiation of naïve T-lymphocytes into T-regulatory lymphocytes, which induce immune tolerance $[18,19]$. Cancer cells harness the inhibitory functions of PD-1 activation by expressing PD-L1 and PD-L2, which limits antitumor immune responses [20]. PD-1 can also be expressed on tumor-associated macrophages, which may lead to a tumor microenvironment that is conducive to cancer progression [21].

Optimal T-lymphocyte activity requires binding of costimulatory molecules such as CD28, expressed on the T-lymphocyte cell surface, to its receptors B7-1 (CD80) and B7-2 (CD86), expressed on antigen presenting cells [22, 23]. CTLA-4 is a CD28 homolog that has a higher affinity for $\mathrm{B} 7$ than $\mathrm{CD} 28$, but does not produce a stimulatory signal. CTLA-4 has a 36-amino acid cytoplasmic tail that lacks enzymatic activity, but also has an immunoreceptor tyrosine-based inhibitory motif that has inhibitory functions [24, 25]. Activation of CTLA-4 induces signals that inhibit T-lymphocyte function [23, 26-29], decrease T-lymphocyte proliferation, and impair secretion of interleukin-2 [22, 23, 26, 27, 30]. In health, CTLA-4 is mainly expressed by T-regulatory cells and CTLA-4 activation is an important mechanism to promote peripheral tolerance [31]. Loss of CTLA-4 function leads to fatal autoimmunity in mice [32, 33]. Similarly, cancer cells express CTLA-4 on the tumor surface, which leads to impaired T-cell function and survival $[34,35]$.

\section{Immune Checkpoint Inhibition as a Therapeutic Strategy in Cancer}

Cancer cells harness checkpoint activation through the PD-1 and CTLA-4 pathways to induce energy in antitumor lymphocytes. Inhibition of these pathways can lead to tumor regression. In this section, we will briefly discuss the CTLA-4 inhibitor: ipilimumab, the PD-1 inhibitors: nivolumab and pembrolizumab, and the PD-L1 inhibitors: atezolizumab, avelumab, and durvalumab. Ipilimumab is the only CTLA-4 inhibitor approved by the Food and Drug Administration (FDA) at this time. Ipilimumab binds to the front $\beta$-sheet of CTLA- 4 and interferes with the formation of CTLA-4:B7 complexes [36]. Another CTLA-4 inhibitor, tremelimumab, is in development, but not yet approved by the FDA and is beyond the scope of this chapter. Inhibitors of the PD-1 pathway broadly fall into two categories: inhibitors of PD-1 function and inhibitors of PD-L1 function. Nivolumab and pembrolizumab bind competitively to PD-1 to form PD-1: monoclonal antibody complexes [37]. These two drugs bind to PD-1 in slightly different orientations. Atezolizumab, avelumab, and durvalumab bind 
to PD-L1 in different orientations and interfere with the formation of PD-L1 and CD-80:B7.1 complexes, without inhibiting the PD-L2/PD-1 pathway. The FDA has approved several PD-1 and PD-L1 inhibitors to treat many tumor types and several more trials of ICI therapy are underway. Further details about current FDAapproved immune checkpoint inhibitors and their indications can be found in chapter 1 .

\section{Clinical and Radiologic Patterns of Pneumonitis}

In the following section, we discuss presentations of pneumonitis after immune checkpoint inhibitor (ICI) therapy. Pneumonitis is a rare irAE after ICI therapy that presents as an interstitial lung disease [38]. Pneumonitis after ICI therapy presents in four patterns: organizing pneumonia (OP), nonspecific interstitial pneumonia (NSIP), hypersensitivity pneumonitis (HP), and diffuse alveolar damage (DAD).

For the purposes of this chapter, we will combine NSIP and HP into one category, due to similarities in presentation and in therapeutic approaches. Table 13.1 summarizes the clinical, radiological, and pathological features associated with each pattern of pneumonitis, and Fig. 13.1 shows characteristic images from chest computed tomography (CT) scans. A more complete discussion of the clinical features and pathophysiology of various ILDs is available elsewhere [39, 40].

OP OP is a common manifestation of pneumonitis after ICI therapies [41]. OP primarily affects distal bronchioles, respiratory bronchioles, alveolar ducts, and alveolar walls [42]. Symptoms of OP may include low-grade fever, malaise, and cough, and the onset of symptoms in idiopathic cases is often subacute [43-46]. Respiratory infections are often associated with the development of OP, though the mechanism remains unclear [47]. Thoracic CT imaging of patients with OP primarily appears as ground-glass or consolidative opacities which are more predominant in the lung periphery in subpleural regions [48]. The reverse halo sign, which is character- ized by ground-glass opacities surrounded by denser consolidative opacities, can be seen in OP but is not pathognomonic [49]. The extent of radiological involvement can vary substantially from case to case. The histology of OP is characterized by excessive proliferation of plugs of granulation tissue (Fig. 13.2) in distal airspaces with infiltration by lymphocytes and plasma cells [48]. These plugs consist of loose collage, fibroblasts, and myofibroblasts. Bronchoalveolar lavage (BAL) is often performed in OP to rule out infection, though a BAL inflammatory signature is not sufficient to diagnose OP [48]. The treatment of OP depends upon the severity of the disease. We recommend use of the Common Terminology Criteria for Adverse Events (CTCAE, Table 13.2) to grade the severity of pneumonitis [50]. Mild cases (Grade 1) of OP may resolve spontaneously, but close monitoring for early signs of pulmonary impairment is imperative [51]. Patients with pneumonitis of grade 2 or higher should be treated with corticosteroid therapy. Corticosteroids are highly efficacious in $\mathrm{OP}$, and treatment doses typically start at $0.5-1 \mathrm{mg} / \mathrm{kg} /$ day of prednisone or equivalent for 3-6 months. Interruptions in corticosteroid treatment may result in relapse of OP [52].

Noncorticosteroid therapies, such as cyclosporine, rituximab, and macrolides, have been associated with anecdotal success in small case series of steroid-refractory patients but are not typically used [53-56]. Current guidelines recommend immunosuppressive agents, such as infliximab, cyclophosphamide, mycophenolate mofetil, and intravenous immunoglobulin, for treatment of pneumonitis that does not improve with corticosteroid therapy, but these recommendations are also based on case reports or small case series [115, 132-134]. Infliximab has been reported to be effective in severe pneumonitis, but this requires validation in a prospective study [41]. Tocilizumab, an interleukin-6 receptor antagonist, may be a viable option for treatment of steroid-refractory pneumonitis. For example, in a single center study, of the 87 patients who were treated with nivolumab, 34 were given tocilizumab for high-grade immune-related adverse events that were refractory to corticoste- 
Table 13.1 Clinical, radiological, and histopathological features of common patterns of pneumonitis

\begin{tabular}{|c|c|c|c|c|}
\hline Type & Clinical features & Radiological features & $\begin{array}{l}\text { Histopathological } \\
\text { features }\end{array}$ & Treatment \\
\hline $\begin{array}{l}\text { Organizing } \\
\text { pneumonia } \\
(\mathrm{OP})\end{array}$ & $\begin{array}{l}\text { Nonproductive } \\
\text { cough, dyspnea, } \\
\text { weight loss, usually } \\
\text { for less than } 2 \\
\text { months }\end{array}$ & $\begin{array}{l}\text { Patchy areas of } \\
\text { consolidation or } \\
\text { ground-glass opacities } \\
\text { which are often seen in } \\
\text { the periphery. Multiple } \\
\text { alveolar opacities, } \\
\text { solitary opacities, or } \\
\text { infiltrative opacities can } \\
\text { be seen }\end{array}$ & $\begin{array}{l}\text { Proliferation of } \\
\text { granulation tissues in } \\
\text { the distal bronchus and } \\
\text { alveoli along with mild } \\
\text { to moderate infiltration } \\
\text { of plasma cells and } \\
\text { lymphocytes }\end{array}$ & $\begin{array}{l}\text { Mild OP with no } \\
\text { pulmonary function } \\
\text { Impairment - } \\
\text { resolution can occur } \\
\text { spontaneously, but } \\
\text { requires close } \\
\text { monitoring of } \\
\text { respiratory symptoms, } \\
\text { imaging, and/or } \\
\text { pulmonary function. } \\
\text { Progressive and/or } \\
\text { persistent symptoms } \\
\text { with evidence of } \\
\text { pulmonary function } \\
\text { Impairment - } \\
\text { corticosteroid therapy } \\
\text { with doses usually } \\
\text { starting at } 0.5-1 \text { mg/ } \\
\text { kg/day of prednisone } \\
\text { or equivalent for } \\
3 \text {-6 months }\end{array}$ \\
\hline $\begin{array}{l}\text { Nonspecific } \\
\text { interstitial } \\
\text { pneumonia } \\
\text { (NSIP) }\end{array}$ & $\begin{array}{l}\text { Nonproductive } \\
\text { cough, dyspnea, } \\
\text { which develops over } \\
\text { weeks to months. } \\
\text { Bibasilar crackles } \\
\text { are also heard in } \\
\text { majority of patients }\end{array}$ & $\begin{array}{l}\text { Reticular markings, } \\
\text { traction bronchiectasis, } \\
\text { and ground-glass } \\
\text { opacities are seen } \\
\text { mostly in lower zones }\end{array}$ & $\begin{array}{l}\text { Fibrosis with diffuse } \\
\text { inflammatory cell } \\
\text { infiltration and uniform } \\
\text { and diffuse thickening } \\
\text { of alveolar walls, but } \\
\text { without loss of alveolar } \\
\text { structural integrity }\end{array}$ & $\begin{array}{l}\text { Patients with minimal } \\
\text { symptoms and no } \\
\text { change in pulmonary } \\
\text { function-observation } \\
\text { Moderate symptoms } \\
\text { or impairment in } \\
\text { pulmonary function } \\
\text { test- corticosteroid } \\
\text { therapy ( } 0.5-1 \mathrm{mg} / \mathrm{kg} / \\
\text { day of prednisone or } \\
\text { equivalent) for } \\
8-12 \text { weeks } \\
\text { Steroid-refractory } \\
\text { disease - Therapy } \\
\text { with intravenous } \\
\text { corticosteroids and/or } \\
\text { cytotoxic therapies }\end{array}$ \\
\hline $\begin{array}{l}\text { Diffuse } \\
\text { alveolar } \\
\text { damage } \\
\text { (DAD) }\end{array}$ & $\begin{array}{l}\text { Rapid onset of } \\
\text { progressive dyspnea } \\
\text { and cough over days } \\
\text { to weeks }\end{array}$ & $\begin{array}{l}\text { Widespread airspace } \\
\text { opacities may be more } \\
\text { prominent in the } \\
\text { dependent areas of the } \\
\text { lung }\end{array}$ & $\begin{array}{l}\text { Alveolar thickening } \\
\text { with hyaline membrane } \\
\text { deposition and } \\
\text { infiltration with } \\
\text { inflammatory cells }\end{array}$ & $\begin{array}{l}\text { Supportive therapies } \\
\text { for patients with } \\
\text { respiratory failure and } \\
\text { intravenous high-dose } \\
\text { corticosteroids }\end{array}$ \\
\hline
\end{tabular}

roid therapy. Of those, 27 patients (around 80\%) showed clinical improvement and the median time to discharge was 4 days [128]. Anakinra is an interleukin-1 receptor antagonist used for the treatment of inflammatory disorders, such as rheumatoid arthritis. Anakinra inhibits interleukin-1 signaling by competitively binding to IL-1R and blocking both IL- $1 \alpha$ and IL- $1 \beta$ activity. Using anakinra to block the interleukin-1 pathway may be another viable option for treat- ment of steroid-refractory pneumonitis. Further randomized clinical trials exploring these immunosuppressive therapies are needed. In general, at least temporary cessation of ICI therapy is recommended to allow for resolution of pneumonitis.

NSIP NSIP is a rare ILD that is often associated with autoimmune diseases or human immunodeficiency virus infection, and along with OP, 

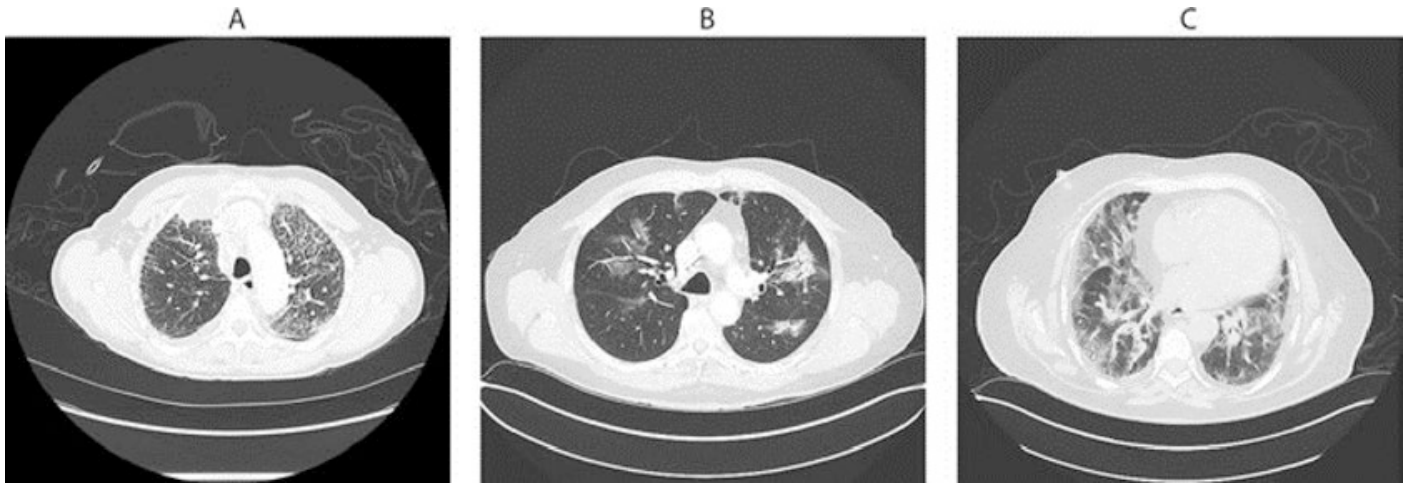

Fig. 13.1 Representative images of (a) nonspecific interstitial pneumonitis, (b) organizing pneumonia, and (c) diffuse alveolar damage in patients receiving precision oncology therapies

Fig. 13.2 Buds of granulation tissue (arrows) in the lumen of alveoli. (Reproduced with permission from Clinical Respiratory Medicine, Cottin V. and Cordier J., 2012, Elsevier Publishing)

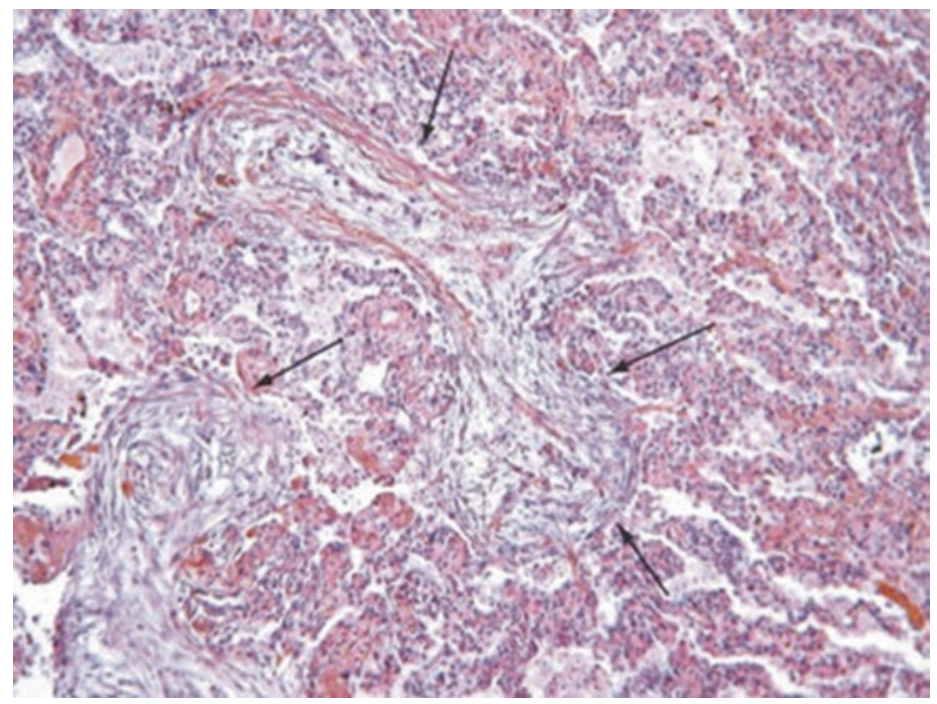

is a common manifestation of pneumonitis after ICI therapy [57]. NSIP typically presents with nonspecific symptoms of cough and dyspnea, though the duration of symptoms may vary from case to case. Thoracic CT imaging of NSIP typically reveals ground-glass opacities, reticular infiltrates, and traction bronchiectasis [58-60]. Subpleural sparing of lung infiltrates may help distinguish NSIP from idiopathic pulmonary fibrosis [61]. The HP variant of ICI-related pneumonitis may be characterized by air trapping on expiratory chest CT imaging [62]. However, unlike HP, which occurs in the general population, there is no clear link to pulmonary exposures, such as aerosolized molds [63] or toxic chemicals [64]. Histologically, NSIP is characterized by dense fibrosis with diffuse inflammatory cell infiltration and uniform and diffuse thickening of alveolar walls, but unlike idiopathic pulmonary fibrosis, there is no loss of alveolar integrity [65]. Fibroblastic foci may be present, but are less common in cases of NSIP [66]. The HP variant of pneumonitis may be characterized by poorly formed noncaseating granulomas [62]. In general, patients who develop NSIP after ICI therapy require corticosteroid therapy $(0.5-1 \mathrm{mg} / \mathrm{kg} /$ day of prednisone or equivalent) for 8-12 weeks. Steroidrefractory disease is more commonly seen in NSIP than in OP and may require further therapy with intravenous corticosteroids and/or cytotoxic therapies [51]. For ICI-related NSIP, interruption of ICI therapy is generally recommended [67]. 
Table 13.2 Grading of pneumonitis as outlined by the Common Terminology Criteria for Adverse Events v5.0

\begin{tabular}{l|l|l|l|l|l}
\hline Grade & Grade 1 & Grade 2 & Grade 3 & Grade 4 & Grade 5 \\
\hline Symptoms & Asymptomatic & $\begin{array}{l}\text { Symptomatic, } \\
\text { limiting } \\
\text { instrumental } \\
\text { activities of daily } \\
\text { living }\end{array}$ & $\begin{array}{l}\text { Severe symptoms, } \\
\text { limiting self-care } \\
\text { activities of daily } \\
\text { living }\end{array}$ & $\begin{array}{l}\text { Life-threatening } \\
\text { respiratory } \\
\text { compromise }\end{array}$ & Death \\
\hline $\begin{array}{l}\text { Intervention } \\
\text { required }\end{array}$ & $\begin{array}{l}\text { Clinical or diagnostic } \\
\text { observations only; } \\
\text { intervention not } \\
\text { indicated }\end{array}$ & $\begin{array}{l}\text { Medical } \\
\text { intervention } \\
\text { indicated }\end{array}$ & $\begin{array}{l}\text { Medical } \\
\text { intervention and } \\
\text { oxygen are } \\
\text { indicated }\end{array}$ & $\begin{array}{l}\text { Urgent medical } \\
\text { intervention is } \\
\text { indicated (e.g., } \\
\text { tracheostomy or } \\
\text { intubation) }\end{array}$ & \\
\hline
\end{tabular}

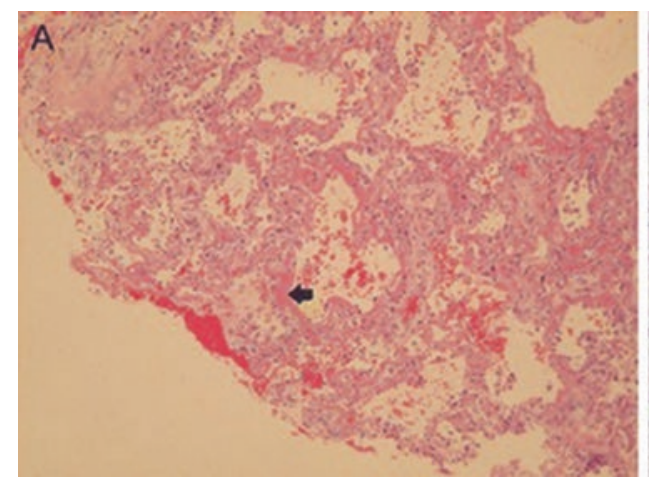

Fig. 13.3 Pathological findings of diffuse alveolar damage. (a) Diffuse alveolar damage in the acute phase. The interstitium is edematous. Hyaline membrane (arrow) is seen lining the alveolar ducts (hematoxylin and eosin

DAD DAD is a severe form of pneumonitis caused by widespread alveolar injury that results in severe capillary leak and noncardiogenic pulmonary edema $[67,68]$. Clinically, the presentation is similar to the acute respiratory distress syndrome (ARDS), characterized by tachypnea, severe hypoxemia, and widespread alveolar infiltrates. Typically, this occurs more rapidly than OP or NSIP, with the onset of symptoms rapidly progressing in days. The presence of DAD in the histological examination may not always correlate with ARDS. For example, only one-half of patients that had DAD were clinically diagnosed with ARDS in several open lung biopsies or autopsy studies [71, 122, 124-126]. Though histology is difficult to obtain due to the severity of illness, the histopathologic appearance of diffuse alveolar damage (DAD) is characterized by the formation of thickened alveolar membranes, hya-

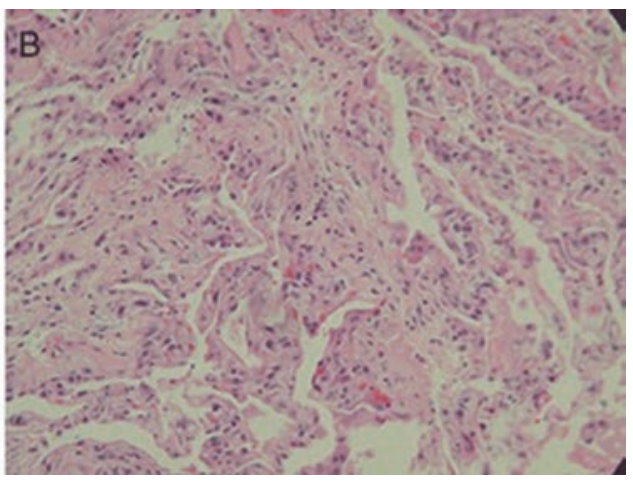

stain, $\times 100$ ). (b) Diffuse alveolar damage in the organizing phase. The interstitium is thickened with organizing connective tissue. Prominent type 2 pneumocyte hyperplasia is seen (hematoxylin and eosin stain, $\times 200$ ) [71]

line membrane deposition, and infiltration with inflammatory cells (Fig. 13.3) [69, 70]. The acute phase of DAD is characterized by inflammation and edema of alveolar structures, while the organizing phase is characterized by the deposition of collagen by fibroblasts [71]. Thoracic CT images of DAD show widespread airspace opacities, which may be more prominent in the dependent areas of the lung [72-74]. Other diseases may mimic drug-induced DAD and should be ruled out. Pulmonary infections and eosinophilic pneumonias may be ruled out by analysis of BAL fluid, while congestive heart failure should be ruled out with a thorough clinical examination, echocardiography, and potentially right heart catheterization. Supportive therapies, including noninvasive or invasive mechanical ventilation, are often necessary to treat respiratory failure associated with DAD. Early initiation of high- 
dose systemic corticosteroids is generally recommended, although data supporting this practice is very limited. Mortality rates remain high despite aggressive therapy [75].

\section{Clinical Approach to the Evaluation of ICI-Related Pneumonitis}

Because symptoms of pneumonitis may be subtle and masked by other comorbid symptoms associated with the underlying cancers (e.g., large lung cancers or widespread pulmonary metastases), we advise clinicians that evaluate and treat patients who are on ICI therapies have a low threshold for initiating a thorough evaluation for pneumonitis. Symptoms such as dyspnea, cough, fever, and chest pain should raise the suspicion for pneumonitis [76, 77]. We recommend thoracic imaging and pulmonary function testing. Chest radiography is not sufficiently sensitive to detect subtle findings of pneumonitis; therefore, symptomatic patients should be referred for thoracic CT imaging [78]. Radiation doses associated with thoracic $\mathrm{CT}$ are low with modern scanners, making serial thoracic imaging a safe and effective method to evaluate progression or resolution of pneumonitis [79]. Pulmonary function testing should be performed at the time of evaluation, as early impairment in pulmonary function may herald the onset of pneumonitis [80]. Furthermore, in patients with confirmed pneumonitis, pulmonary function should be monitored serially to evaluate for progression or resolution of pneumonitis. Early consultation with pulmonary experts is recommended, and bronchoscopy with BAL should be performed early in the course of the evaluation of patients who are suspected of having ICI-related pneumonitis in order to rule out alternative diagnoses, such as infectious pneumonia. Surgical biopsies of the involved lung parenchyma should be considered in select patients to evaluate the histopathological features of pneumonitis. Transbronchial biopsies are generally not recommended due to poor sensitivity for the detection of ILD [81].

\section{Incidence and Clinical Characteristics of Pneumonitis After ICI Therapy}

The incidence of pneumonitis varies with the specific agent. For example, in clinical trials, pneumonitis rates have been reported in about $1 \%$ of patients treated with ipilimumab, while the incidence with PD-1 and PD-L1 inhibitor monotherapy has been reported in about 3-5\%. The incidence of pneumonitis with combination therapy with PD-1 or PD-L1 inhibitors and CTLA-4 inhibitors is reported to be as high as $10 \%$ [82-86]. In general, the median onset of pneumonitis is about 3 months [41, 87-89]. Pneumonitis after ICI therapy generally presents as OP or NSIP, but may rarely present as DAD and can have a fulminant course. In this section, we discuss incidence rates and specific forms of pneumonitis that occur with each FDAapproved ICI therapy.

\section{CTLA-4 Inhibitors}

Ipilimumab is the only CTLA-4 inhibitor approved by the FDA at the time of this writing. The incidence of pneumonitis with ipilimumab is low, with pneumonitis of any grade occurring in $1.3 \%$ of treated patients, and high-grade (grades 3 or 4 ) pneumonitis occurring in $0.3 \%$ of treated patients [90]. The median time from treatment initiation to the onset of pneumonitis has been reported to be around 2.3 months, and the most common pattern of pneumonitis is OP [91]. While some irAEs are more common with CTLA-4 inhibitors than PD-1 or PD-L1 inhibitors [92, 93], pneumonitis is less common, though the mechanism for this difference is unclear [94]. Pneumonitis occurs at about onethird the rate in patients treated with ipilimumab for melanoma treatment as compared to those being treated for renal cell cancer or non-small cell lung cancer [94]. One possibility for this may be the presence of lung disease from cigarette smoking, as has been described in other ILDs [95]. 


\section{PD-1 and PD-L1 Inhibitors}

In this section, we will discuss the PD-1 inhibitors: nivolumab and pembrolizumab, and the PD-L1 inhibitors: atezolizumab, avelumab, and durvalumab. Pneumonitis after PD-1 inhibition occurs as much three times more frequently as compared to conventional chemotherapy regimens across several types of cancers [96].

Recent studies show the incidence for allgrade pneumonitis for PD-1 inhibitors in clinical trials is around $3 \%$, with most studies reporting incidence rates of $3-5 \%[82,84,96]$. The incidence of high-grade (grade 3 or higher by CTCAE criteria) pneumonitis for PD-1 inhibitors in clinical trials is around $1-1.5 \%$ [82, 84, 96]. However, the pneumonitis rate seems to vary between different tumor types. For example, the rate of any-grade pneumonitis and high-grade pneumonitis in renal cell cancer (any: $4.4 \%$, high: $1.7 \%$ ) and non-small cell lung cancer (any: 4.3\%, high: $2.0 \%$ ) are higher than in studies of melanoma (any: 1.4\%, high: 0.9\%) [96].

Similar to ipilimumab, the incidence of pneumonitis after PD-1 inhibition seems to be higher in smoking-related cancers. In a case-control study of patients who developed pneumonitis after PD-1 inhibitor therapy, smoking status was not associated with the risk of pneumonitis, but a history of COPD or lung radiotherapy was predictive of pneumonitis [97]. However, there does not appear to be any difference in the incidence of pneumonitis by PD-1 inhibitor dosage, suggesting that irAEs are not directly tied to these therapies in a dose-dependent fashion [96]. This is consistent with our observation that pneumonitis after PD-1/PD-L1 axis inhibition appears to be an idiosyncratic phenomenon.

Rates of pneumonitis may be higher when considering patients being treated outside the controlled context of clinical trials. In a single center study of 204 patients that included both clinical-trial-enrolled and non-clinical-trialenrolled patients with NSCLC, the incidence of any-grade pneumonitis was $19 \%$ and high-grade pneumonitis was $11 \%$ [130]. The median time of progression to pneumonitis was 6.3 months after starting immunotherapy. Furthermore, data from the same group showed that the development of pneumonitis is associated with impaired survival in NSCLC patients [129]. In this cohort, patients with adenocarcinoma who developed pneumonitis had higher mortality than those with nonadenocarcinoma histology (squamous or other). Similarly, a retrospective study from a large, comprehensive cancer center reported that patients who presented to the emergency department for PD-1/PD-L1 pneumonitis were associated with poor overall survival compared to patients who developed other irAEs, such as colitis [123].

Concurrent treatment with ICI and conventional therapies may also result in higher rates of pneumonitis. In a phase III randomized trial exploring durvalumab after concurrent chemoradiotherapy in stage III non-small cell lung cancer (NSCLC), the pneumonitis rate, which included pneumonitis from an irAE or secondary to radiation pneumonitis or as a consequence of combination of both, was reported as $34 \%$, compared to $25 \%$ in placebo arm. Pneumonitis was the most frequent adverse event leading to the discontinuation of the trial regimen $(4.8 \%$ of patients in the durvalumab group and in $2.6 \%$ of those in the placebo group) [121].

Recent studies suggest that pneumonitis after PD-L1 inhibitor therapy may occur less frequently than after PD-1 inhibitor therapy. For example, in a pooled analysis of data from phase 1 and phase II trials, the overall incidence of anygrade pneumonitis for avelumab in patients with advanced solid tumors was around $1.2 \%$ [131]. Similarly, Pillai et al. and Khunger et al. both reported that the incidence of any-grade pneumonitis was higher in NSCLC patients treated with PD-1 inhibitors as compared to PD-L1 inhibitors (PD-1 vs PD-L1: around 4\% vs around 2\%) [83, 127]. There are several caveats that could cause these results to be prone to bias. Both randomized and single-arm, open-label trials with varying doses of PD-1/PD-L1 inhibitors were included. Additionally, patients included in these trials were not always similar. For example, some trials enrolled treatment-naïve patients, while the majority of the trials enrolled previously treated patients, which could influence the tolerability of 
the treatment. In addition, there is limited data from randomized, controlled trials that directly compare the toxicities of PD-1 and PD-L1 inhibitors. Further studies are needed to better understand the incidence of pneumonitis, particularly as these therapies are approved for new cancers.

\section{Combination Therapy with PD-1/ PD-L1 Inhibitors and CTLA-4 Inhibitors}

By inhibiting both the CTLA-4 and PD-1 pathways, it is possible to achieve greater immune activation, which may increase antitumor responses in certain cancers [98]. However, this also increases the risk for irAEs, including pneumonitis. Compared to monotherapy, the incidence of pneumonitis with combination therapy may be as high as $10 \%$ and the time to onset is usually sooner [84]. Naidoo et al. found that the median time to pneumonitis onset was 2.7 months in patients receiving combination ICI therapy as opposed to 4.6 months in those receiving ICI monotherapy [84]. Wu et al. found a similarly higher incidence of pneumonitis with combination ICI therapy as compared to ICI monotherapy. In combination ICI therapy, the incidence of pneumonitis was almost 7\% and the incidence of high-grade pneumonitis was almost $2 \%$ [96]. This suggests that when compared to ICI monotherapy, combination ICI therapy results in a higher risk for any-grade and high-grade pneumonitis and a faster onset to pneumonitis in patients in whom this develops. ICI therapies often have durable effects due the induction of immunologic memory [99]. As a result, sequential treatment with PD-1/PD-L1 inhibitors and CTLA-4 inhibitors may have a similar increase in the risk of pneumonitis as with combination ICI therapy, where both PD-1/PD-L1 inhibitors are given at the same time. In a small study of 40 patients who received nivolumab or pembrolizumab followed by ipilimumab, Bowyer et al. found that $8 \%$ of patients experienced high-grade pneumonitis [100]. This finding needs to be confirmed in a larger study cohort, but suggests that when ICI therapies are given sequentially, the risk of pneumonitis is similar to combination therapy.

\section{Radiologic Patterns of Pneumonitis After ICI Therapy}

Pneumonitis after ICI therapy typically presents as NSIP or OP. In clinical practice, in a cohort of 915 patients who received ICI monotherapies or combination therapies, the most common pattern of pneumonitis was NSIP (18/27), followed by OP $(5 / 27)$. Others have shown that OP is more common after PD-1 [41] or CTLA-4 inhibitor therapy [91]. DAD reactions are rarer and typically have a more severe clinical course, but may still be managed with prompt initiation of immunosuppression.

Other manifestations of pulmonary irAEs have been described in the literature. Airway inflammation with bronchiolitis has been described in a patient who was receiving nivolumab for non-small cell lung cancer [101]. Rapidly recurrent pleural and pericardial effusions were reported in two patients within 8 weeks of initiating nivolumab therapy [102]. An increased incidence of pleural effusions was also noted in the early clinical trials of nivolumab therapy in patients with non-small cell lung cancer, although these effusions could not be definitely attributed to nivolumab, as opposed to progression of disease [103]. ICI-related pleural and pericardial fluid accumulation may be a form of irAE or a form of pseudoprogression. Drug interruption and management of pleural/pericardial drainage procedures are the primary focus of treatment. Initiation of immunosuppressive therapy for recalcitrant effusions is reasonable, although the role of steroids in this setting has not been established.

Sarcoid-like reactions have been observed with ipilimumab [91, 104, 105] and with PD-1 inhibition [106, 107]. Sarcoid-like reactions are rare irAEs, and the manifestations vary from case to case. Presentations may include mediastinal lymphadenopathy, pulmonary infiltrates, skin rashes, and renal disease. While these reactions may resemble sarcoidosis clinically, the 
immunology is not necessarily identical to sarcoidosis, which occurs in the general population [104, 108]. However, inhibition of immune checkpoint pathways may increase the population of Th17 cells, which are thought to be involved in non-ICI-related sarcoidosis [109, 110]. Therefore, there is a plausible biological basis for the incidence of sarcoid-like reactions in patients treated with ICI inhibitors. Treatment includes interruption of ICI treatment and systemic steroids. Further work is necessary to understand the incidence of sarcoid-like reactions after ICI therapies.

\section{Areas of Uncertainty}

\section{Rechallenge with ICI Therapies After the Occurrence of Pneumonitis}

A key question in patients receiving ICI therapy is whether the onset of irAEs, such as pneumonitis, may indicate a more favorable response to treatment. Some groups have found that patients who experience irAEs have a better treatment response [89, 111], while others have not [112]. Therefore, rechallenge with ICI therapies after the occurrence of ICI-related pneumonitis may be desirable. Several groups have reported the safety of resuming ICI therapy after irAEs [113, 114]. Additionally, the overall incidence of irAEs is higher upon drug rechallenge, with about half of patients experiencing any-grade irAEs. Furthermore, about $20 \%$ of patients experience irAEs which are different from the initial irAE [114]. In other words, patients who develop pneumonitis after ICI therapies may experience a nonpneumonitis irAE upon drug rechallenge. Generally, these events are treatable with corticosteroids and are not fatal [89], though rare fatalities have been reported [114]. However, it is not clear whether ICI rechallenge is of sufficient clinical benefit to warrant the risk of recurrent irAEs [35]. The Society for Immunotherapy of Cancer recommends that drug rechallenge can remain an option in patients with grade 2 pneumonitis, which has resolved completely, as well as in select patients with grade 3 pneumonitis, which has resolved completely and in whom the benefits of ICI therapies outweigh the risks of recurrent irAEs [115]. Patients with grade 4 pneumonitis should not undergo rechallenge with ICI therapies. Further work in this area is necessary to guide practice algorithms.

\section{Biomarkers to Identify Patients at Risk for Pneumonitis}

As noted earlier in this chapter, certain patients may be at higher risk for the initiation of pneumonitis. In particular, patients with preexisting lung injury from smoking or from radiation may bear a higher risk for ICI-related pneumonitis. Recent advances in imaging techniques have allowed thoracic $\mathrm{CT}$ images to be analyzed at the voxel level to detect textural features which are associated with disease or health [116]. A similar approach led to the development of a radiomicbased algorithm, which predicted the onset of pneumonitis from pretreatment thoracic CT scans of patients who underwent ICI therapies [117]. These findings need to be externally validated but highlight the power of imaging as a biomarker of disease risk.

Interleukin-17 is an inflammatory cytokine that is upregulated in many autoimmune diseases, including inflammatory bowel disease [118]. Elevated serum IL-17 levels were predictive of colitis in patients with melanoma treated with ipilimumab [119]. Similarly, in patients with leukemia, Th1/Th17 cells are expanded in bronchoalveolar lavage fluid from patients with leukemia who developed pneumonitis after ICI therapy as compared to control patients with leukemia who had not received ICI therapy [120]. Further work is necessary to identify inflammatory biomarkers in the blood or in the bronchoalveolar lavage fluid that can help predict the onset of pneumonitis after ICI therapy. 


\section{Conclusions}

Pneumonitis is a rare but serious irAE that occurs after therapy with PD-1, PD-L1, and CTLA-4 inhibitors. Pneumonitis should be recognized promptly if patients have new pulmonary symptoms, such as cough or shortness of breath. The workup in patients with suspected pneumonitis should include pulmonary function testing, thoracic CT imaging, and bronchoscopy with bronchoalveolar lavage to rule out infection. Treatment with corticosteroids is generally effective and results in prompt resolution of symptoms. However, untreated pneumonitis can be fatal. Further work is needed to identify which patients are at the highest risk for the development of pneumonitis after ICI therapies.

\section{References}

1. Ahmad AS, Ormiston-Smith N, Sasieni PD. Trends in the lifetime risk of developing cancer in Great Britain: comparison of risk for those born from 1930 to 1960. Br J Cancer. 2015;112(5):943-7.

2. Miller KD, Siegel RL, Lin CC, Mariotto AB, Kramer JL, Rowland JH, et al. Cancer treatment and survivorship statistics, 2016. CA Cancer J Clin. 2016;66(4):271-89.

3. Baxevanis CN, Perez SA, Papamichail M. Cancer immunotherapy. Crit Rev Clin Lab Sci. 2009;46(4):167-89.

4. Farkona S, Diamandis EP, Blasutig IM. Cancer immunotherapy: the beginning of the end of cancer? BMC Med. 2016;14:73.

5. Dillman RO. Cancer immunotherapy. Cancer Biother Radiopharm. 2011;26(1):1-64.

6. Oiseth SJ, Aziz MS. Cancer immunotherapy: a brief review of the history, possibilities, and challenges ahead. J Cancer Metastasis Treat. 2017;3(10):250-61

7. Finn OJ. Immuno-oncology: understanding the function and dysfunction of the immune system in cancer. Ann Oncol. 2012;23(Suppl 8):viii6-9.

8. Sharma P, Allison JP. Immune checkpoint targeting in cancer therapy: toward combination strategies with curative potential. Cell. 2015;161(2):205-14.

9. Barber DL, Wherry EJ, Masopust D, Zhu B, Allison JP, Sharpe AH, et al. Restoring function in exhausted CD8 T cells during chronic viral infection. Nature. 2006;439(7077):682-7.

10. Francisco LM, Sage PT, Sharpe AH. The PD-1 pathway in tolerance and autoimmunity. Immunol Rev. 2010;236:219-42.
11. Keir ME, Butte MJ, Freeman GJ, Sharpe AH. PD-1 and its ligands in tolerance and immunity. Annu Rev Immunol. 2008;26:677-704.

12. Fife BT, Pauken KE. The role of the PD-1 pathway in autoimmunity and peripheral tolerance. Ann N Y Acad Sci. 2011;1217:45-59.

13. Ishida Y, Agata Y, Shibahara K, Honjo T. Induced expression of PD-1, a novel member of the immunoglobulin gene superfamily, upon programmed cell death. EMBO J. 1992;11(11):3887-95.

14. Parry RV, Chemnitz JM, Frauwirth KA, Lanfranco AR, Braunstein I, Kobayashi SV, et al. CTLA-4 and PD-1 receptors inhibit T-cell activation by distinct mechanisms. Mol Cell Biol. 2005;25(21):9543-53.

15. Freeman GJ, Long AJ, Iwai Y, Bourque K, Chernova $\mathrm{T}$, Nishimura H, et al. Engagement of the PD-1 immunoinhibitory receptor by a novel B7 family member leads to negative regulation of lymphocyte activation. J Exp Med. 2000;192(7):1027-34.

16. Riley JL. PD-1 signaling in primary T cells. Immunol Rev. 2009;229(1):114-25.

17. Latchman Y, Wood CR, Chernova T, Chaudhary D, Borde M, Chernova I, et al. PD-L2 is a second ligand for PD-1 and inhibits T cell activation. Nat Immunol. 2001;2(3):261-8.

18. Francisco LM, Salinas VH, Brown KE, Vanguri VK, Freeman GJ, Kuchroo VK, et al. PD-L1 regulates the development, maintenance, and function of induced regulatory $\mathrm{T}$ cells. J Exp Med. 2009;206(13):3015-29.

19. Amarnath S, Mangus CW, Wang JC, Wei F, He A, Kapoor V, et al. The PDL1-PD1 axis converts human TH1 cells into regulatory T cells. Sci Transl Med. 2011;3(111):111ra20.

20. Wang X, Teng F, Kong L, Yu J. PD-L1 expression in human cancers and its association with clinical outcomes. Onco Targets Ther. 2016;9:5023-39.

21. Gordon SR, Maute RL, Dulken BW, Hutter G, George BM, McCracken MN, et al. PD-1 expression by tumour-associated macrophages inhibits phagocytosis and tumour immunity. Nature. 2017;545(7655):495-9.

22. Buchbinder EI, Desai A. CTLA-4 and PD-1 pathways: similarities, differences, and implications of their inhibition. Am J Clin Oncol. 2016;39(1):98-106.

23. Sharpe AH, Abbas AK. T-cell costimulation-biology, therapeutic potential, and challenges. N Engl J Med. 2006;355(10):973-5.

24. Egen JG, Kuhns MS, Allison JP. CTLA-4: new insights into its biological function and use in tumor immunotherapy. Nat Immunol. 2002;3(7):611-8.

25. Teft WA, Kirchhof MG, Madrenas J. A molecular perspective of CTLA-4 function. Annu Rev Immunol. 2006;24:65-97.

26. Krummel MF, Allison JP. CD28 and CTLA-4 have opposing effects on the response of T cells to stimulation. J Exp Med. 1995;182(2):459-65.

27. Walunas TL, Bakker CY, Bluestone JA. CTLA-4 ligation blocks CD28-dependent T cell activation. J Exp Med. 1996;183(6):2541-50. 
28. Tivol EA, Borriello F, Schweitzer AN, Lynch WP, Bluestone JA, Sharpe AH. Loss of CTLA-4 leads to massive lymphoproliferation and fatal multiorgan tissue destruction, revealing a critical negative regulatory role of CTLA-4. Immunity. 1995;3(5):541-7.

29. Waterhouse P, Penninger JM, Timms E, Wakeham A, Shahinian A, Lee KP, et al. Lymphoproliferative disorders with early lethality in mice deficient in Ctla-4. Science. 1995;270(5238):985-8.

30. Walunas TL, Lenschow DJ, Bakker CY, Linsley PS, Freeman GJ, Green JM, et al. CTLA-4 can function as a negative regulator of $\mathrm{T}$ cell activation. Immunity. 1994;1(5):405-13.

31. Darrasse-Jèze G, Deroubaix S, Mouquet H, Victora GD, Eisenreich T, Yao K-H, et al. Feedback control of regulatory $\mathrm{T}$ cell homeostasis by dendritic cells in vivo. J Exp Med. 2009;206(9):1853.

32. Mandelbrot DA, McAdam AJ, Sharpe AH. B7-1 or B7-2 is required to produce the lymphoproliferative phenotype in mice lacking cytotoxic T lymphocyteassociated antigen 4 (CTLA- 4). J Exp Med. 1999;189(2):435-40.

33. Piccirillo CA, Shevach EM. Naturally-occurring CD4+CD25+ immunoregulatory $\mathrm{T}$ cells: central players in the arena of peripheral tolerance. Semin Immunol. 2004;16(2):81-8.

34. Syn NL, Teng MWL, Mok TSK, Soo RA. De-novo and acquired resistance to immune checkpoint targeting. Lancet Oncol. 2017;18(12):e731-e41.

35. Schadendorf D, Hodi FS, Robert C, Weber JS, Margolin K, Hamid O, et al. Pooled analysis of longterm survival data from phase II and phase III trials of ipilimumab in unresectable or metastatic melanoma. J Clin Oncol. 2015;33(17):1889-94.

36. Ramagopal UA, Liu W, Garrett-Thomson SC, Bonanno JB, Yan Q, Srinivasan M, et al. Structural basis for cancer immunotherapy by the first-in-class checkpoint inhibitor ipilimumab. Proc Natl Acad Sci U S A. 2017;114(21):E4223-E32.

37. Tan S, Zhang H, Chai Y, Song H, Tong Z, Wang $\mathrm{Q}$, et al. An unexpected N-terminal loop in PD-1 dominates binding by nivolumab. Nat Commun. 2017;8:14369.

38. Antoniou KM, Margaritopoulos GA, Tomassetti S, Bonella F, Costabel U, Poletti V. Interstitial lung disease. Eur Respir Rev. 2014;23(131):40-54.

39. Lim G, Lee KH, Jeong SW, Uh S, Jin SY, Lee DH, et al. Clinical features of interstitial lung diseases. Korean J Intern Med. 1996;11(2):113-21.

40. Glasser SW, Hardie WD, Hagood JS. Pathogenesis of interstitial lung disease in children and adults. Pediatr Allergy Immunol Pulmonol. 2010;23(1):9-14.

41. Nishino M, Ramaiya NH, Awad MM, Sholl LM, Maattala JA, Taibi M, et al. PD-1 inhibitorrelated pneumonitis in advanced Cancer patients: radiographic patterns and clinical course. Clin Cancer Res. 2016;22(24):6051-60.

42. Epler GR. Bronchiolitis obliterans organizing pneumonia: definition and clinical features. Chest. 1992;102(1 Suppl):2S-6S.
43. Epler GR, Colby TV, McLoud TC, Carrington CB, Gaensler EA. Bronchiolitis obliterans organizing pneumonia. N Engl J Med. 1985;312(3):152-8.

44. Cordier JF, Loire R, Brune J. Idiopathic bronchiolitis obliterans organizing pneumonia. Definition of characteristic clinical profiles in a series of 16 patients. Chest. 1989;96(5):999-1004.

45. Guerry-Force ML, Muller NL, Wright JL, Wiggs B, Coppin C, Pare PD, et al. A comparison of bronchiolitis obliterans with organizing pneumonia, usual interstitial pneumonia, and small airways disease. Am Rev Respir Dis. 1987;135(3):705-12.

46. King T Jr. Organizing pneumonia. In: Schwarz M, King T, editors. Interstitial lung disease. Shelton: People's Medical Publishing House; 2011.

47. Cordier JF. Organising pneumonia. Thorax. 2000;55(4):318-28.

48. Cordier JF. Cryptogenic organising pneumonia. Eur Respir J. 2006;28(2):422-46.

49. Godoy MCB, Viswanathan C, Marchiori E, Truong MT, Benveniste MF, Rossi S, et al. The reversed halo sign: update and differential diagnosis. Br J Radiol. 2012;85(1017):1226-35.

50. Friedman CF, Proverbs-Singh TA, Postow MA. Treatment of the immune-related adverse effects of immune checkpoint inhibitors: a review. JAMA Oncol. 2016;2(10):1346-53.

51. Wells AU, Hirani N. Interstitial lung disease guideline. Thorax. 2008;63(Suppl 5):v1-v58.

52. Bradley B, Branley HM, Egan JJ, Greaves MS, Hansell DM, Harrison NK, et al. Interstitial lung disease guideline: the British Thoracic Society in collaboration with the Thoracic Society of Australia and New Zealand and the Irish Thoracic Society. Thorax. 2008;63(Suppl 5):v1-58.

53. Pathak V, Kuhn JM, Durham C, Funkhouser WK, Henke DC. Macrolide use leads to clinical and radiological improvement in patients with cryptogenic organizing pneumonia. Ann Am Thorac Soc. 2014;11(1):87-91.

54. Ding QL, Lv D, Wang BJ, Zhang QL, Yu YM, Sun $\mathrm{SF}$, et al. Macrolide therapy in cryptogenic organizing pneumonia: a case report and literature review. Exp Ther Med. 2015;9(3):829-34.

55. Purcell IF, Bourke SJ, Marshall SM. Cyclophosphamide in severe steroid-resistant bronchiolitis obliterans organizing pneumonia. Respir Med. 1997;91(3):175-7.

56. Koinuma D, Miki M, Ebina M, Tahara M, Hagiwara K, Kondo T, et al. Successful treatment of a case with rapidly progressive Bronchiolitis obliterans organizing pneumonia (BOOP) using cyclosporin A and corticosteroid. Intern Med. 2002;41(1):26-9.

57. Romagnoli M, Nannini C, Piciucchi S, Girelli F, Gurioli C, Casoni G, et al. Idiopathic nonspecific interstitial pneumonia: an interstitial lung disease associated with autoimmune disorders? Eur Respir J. 2011;38(2):384-91.

58. Park IN, Jegal Y, Kim DS, Do KH, Yoo B, Shim TS, et al. Clinical course and lung function change of 
idiopathic nonspecific interstitial pneumonia. Eur Respir J. 2009;33(1):68-76.

59. Silva CI, Muller NL, Lynch DA, Curran-Everett D, Brown KK, Lee KS, et al. Chronic hypersensitivity pneumonitis: differentiation from idiopathic pulmonary fibrosis and nonspecific interstitial pneumonia by using thin-section CT. Radiology. 2008;246(1):288-97.

60. Travis WD, Hunninghake G, King TE Jr, Lynch DA, Colby TV, Galvin JR, et al. Idiopathic nonspecific interstitial pneumonia: report of an American Thoracic Society project. Am J Respir Crit Care Med. 2008;177(12):1338-47.

61. Akira M, Inoue Y, Kitaichi M, Yamamoto S, Arai $\mathrm{T}$, Toyokawa K. Usual interstitial pneumonia and nonspecific interstitial pneumonia with and without concurrent emphysema: thinsection CT findings. Radiology. 2009;251(1):271-9.

62. American Thoracic Society/European Respiratory Society International Multidisciplinary Consensus Classification of the Idiopathic Interstitial Pneumonias. This joint statement of the American Thoracic Society (ATS), and the European Respiratory Society (ERS) was adopted by the ATS board of directors, June 2001 and by the ERS Executive Committee, June 2001. Am J Respir Crit Care Med. 2002;165(2):277-304.

63. Malmberg P, Rask-Andersen A, Rosenhall L. Exposure to microorganisms associated with allergic alveolitis and febrile reactions to mold dust in farmers. Chest. 1993;103(4):1202-9.

64. Zeiss CR, Kanellakes TM, Bellone JD, Levitz D, Pruzansky JJ, Patterson R. Immunoglobulin E-mediated asthma and hypersensitivity pneumonitis with precipitating anti-hapten antibodies due to diphenylmethane diisocyanate (MDI) exposure. J Allergy Clin Immunol. 1980;65(5):347-52.

65. Hashisako M, Fukuoka J. Pathology of idiopathic interstitial pneumonias. Clin Med Insights Circ Respir Pulm Med. 2015;9(Suppl 1):123-33.

66. Flaherty KR, Martinez FJ, Travis W, Lynch JP 3rd. Nonspecific interstitial pneumonia (NSIP). Semin Respir Crit Care Med. 2001;22(4):423-34.

67. Schwaiblmair M. Drug induced interstitial lung disease. Open Respir Med J. 2012;6:63-74.

68. Kaarteenaho R, Kinnula VL. Diffuse alveolar damage: a common phenomenon in progressive interstitial lung disorders. Pulm Med. 2011;2011:1.

69. Matthay MA, Zemans RL. The acute respiratory distress syndrome: pathogenesis and treatment. Annu Rev Pathol. 2011;6:147-63.

70. Spira D, Wirths S, Skowronski F, Pintoffl J, Kaufmann S, Brodoefel H, et al. Diffuse alveolar hemorrhage in patients with hematological malignancies: HRCT patterns of pulmonary involvement and disease course. Clin Imaging. 2013;37(4):680-6.

71. Kao KC, Hu HC, Chang CH, Hung CY, Chiu LC, $\mathrm{Li} \mathrm{SH}$, et al. Diffuse alveolar damage associated mortality in selected acute respiratory distress syn- drome patients with open lung biopsy. Crit Care. 2015;19:228.

72. Goodman LR. Congestive heart failure and adult respiratory distress syndrome. New insights using computed tomography. Radiol Clin N Am. 1996;34(1):33-46.

73. Gattinoni L, Presenti A, Torresin A, Baglioni S, Rivolta M, Rossi F, et al. Adult respiratory distress syndrome profiles by computed tomography. J Thorac Imaging. 1986;1(3):25-30.

74. Pelosi P, Crotti S, Brazzi L, Gattinoni L. Computed tomography in adult respiratory distress syndrome: what has it taught us? Eur Respir J. 1996;9(5):1055-62.

75. Rogers S. Spencer's pathology of the lung. Histopathology. 1999;34(5):470.

76. Naidoo J, Page DB, Li BT, Connell LC, Schindler $\mathrm{K}$, Lacouture ME, et al. Toxicities of the anti-PD-1 and anti-PD-L1 immune checkpoint antibodies. Ann Oncol. 2015;26(12):2375-91.

77. Michot JM, Bigenwald C, Champiat S, Collins M, Carbonnel F, Postel-Vinay S, et al. Immunerelated adverse events with immune checkpoint blockade: a comprehensive review. Eur J Cancer. 2016;54:139-48.

78. Claessens YE, Debray MP, Tubach F, Brun AL, Rammaert B, Hausfater P, et al. Early chest computed tomography scan to assist diagnosis and guide treatment decision for suspected communityacquired pneumonia. Am J Respir Crit Care Med. 2015;192(8):974-82.

79. Hammond E, Sloan C, Newell JD Jr, Sieren JP, Saylor M, Vidal C, et al. Comparison of low- and ultralow-dose computed tomography protocols for quantitative lung and airway assessment. Med Phys. 2017;44(9):4747-57.

80. Franzen D, Schad K, Kowalski B, Clarenbach CF, Stupp R, Dummer R, et al. Ipilimumab and early signs of pulmonary toxicity in patients with metastastic melanoma: a prospective observational study. Cancer Immunol Immunother. 2018;67(1):127-34.

81. Raghu G, Mageto YN, Lockhart D, Schmidt RA, Wood DE, Godwin JD. The accuracy of the clinical diagnosis of new-onset idiopathic pulmonary fibrosis and other interstitial lung disease: a prospective study. Chest. 1999;116(5):1168-74.

82. Nishino M, Giobbie-Hurder A, Hatabu H, Ramaiya $\mathrm{NH}$, Hodi FS. Incidence of programmed cell death 1 inhibitor-related pneumonitis in patients with advanced cancer: a systematic review and metaanalysis. JAMA Oncol. 2016;2(12):1607-16.

83. Khunger M, Rakshit S, Pasupuleti V, Hernandez AV, Mazzone P, Stevenson J, et al. Incidence of pneumonitis with use of programmed death 1 and programmed death-ligand 1 inhibitors in non-small cell lung Cancer: a systematic review and meta-analysis of trials. Chest. 2017;152(2):271-81.

84. Naidoo J, Wang X, Woo KM, Iyriboz T, Halpenny D, Cunningham J, et al. Pneumonitis in patients treated 
with anti-programmed death-1/programmed death ligand 1 therapy. J Clin Oncol. 2017;35(7):709-17.

85. Robert C, Long GV, Brady B, Dutriaux C, Maio M, Mortier L, et al. Nivolumab in previously untreated melanoma without BRAF mutation. N Engl J Med. 2015;372(4):320-30.

86. Reck M, Rodríguez-Abreu D, Robinson AG, Hui R, Csőszi T, Fülöp A, et al. Pembrolizumab versus chemotherapy for PD-L1-positive non-small-cell lung cancer. N Engl J Med. 2016;375(19):1823-33.

87. Nishino M, Hatabu H, Hodi FS, Ramaiya NH. Drugrelated pneumonitis in the era of precision cancer therapy. JCO Precision Oncol. 2017;1:1-12.

88. Shohdy KS, Abdel-Rahman O. Risk of pneumonitis with different immune checkpoint inhibitors in NSCLC. Ann Transl Med. 2017;5(17):365.

89. Fujii T, Colen RR, Bilen MA, Hess KR, Hajjar $\mathrm{J}$, Suarez-Almazor ME, et al. Incidence of immune-related adverse events and its association with treatment outcomes: the MD Anderson Cancer Center experience. Investig New Drugs. 2018;36(4):638-46.

90. Kwon ED, Drake CG, Scher HI, Fizazi K, Bossi A, van den Eertwegh AJ, et al. Ipilimumab versus placebo after radiotherapy in patients with metastatic castration-resistant prostate cancer that had progressed after docetaxel chemotherapy (CA184-043): a multicentre, randomised, double-blind, phase 3 trial. Lancet Oncol. 2014;15(7):700-12.

91. Tirumani SH, Ramaiya NH, Keraliya A, Bailey ND, Ott PA, Hodi FS, et al. Radiographic profiling of immune-related adverse events in advanced melanoma patients treated with ipilimumab. Cancer Immunol Res. 2015;3(10):1185-92.

92. Robert C, Schachter J, Long GV, Arance A, Grob JJ, Mortier L, et al. Pembrolizumab versus Ipilimumab in advanced melanoma. N Engl J Med. 2015;372(26):2521-32.

93. Larkin J, Chiarion-Sileni V, Gonzalez R, Grob JJ, Cowey CL, Lao CD, et al. Combined nivolumab and ipilimumab or monotherapy in untreated melanoma. N Engl J Med. 2015;373(1):23-34.

94. Khoja L, Day D, Wei-Wu Chen T, Siu LL, Hansen AR. Tumour- and class-specific patterns of immune-related adverse events of immune checkpoint inhibitors: a systematic review. Ann Oncol. 2017;28(10):2377-85.

95. Ryu JH, Colby TV, Hartman TE, Vassallo R. Smoking-related interstitial lung diseases: a concise review. Eur Respir J. 2001;17(1):122-32.

96. Wu J, Hong D, Zhang X, Lu X, Miao J. PD-1 inhibitors increase the incidence and risk of pneumonitis in cancer patients in a dose-independent manner: a meta-analysis. Sci Rep. 2017;7:44173.

97. Cui P, Liu Z, Wang G, Ma J, Qian Y, Zhang F, et al. Risk factors for pneumonitis in patients treated with anti-programmed death-1 therapy: a case-control study. Cancer Med. 2018;7:4115.

98. Wolchok JD, Chiarion-Sileni V, Gonzalez R, Rutkowski P, Grob JJ, Cowey CL, et al. Overall survival with combined nivolumab and ipi- limumab in advanced melanoma. $\mathrm{N}$ Engl J Med. 2017;377(14):1345-56.

99. Ribas A, Shin DS, Zaretsky J, Frederiksen J, Cornish A, Avramis E, et al. PD-1 blockade expands intratumoral memory $\mathrm{T}$ cells. Cancer Immunol Res. 2016;4(3):194-203.

100. Bowyer S, Prithviraj P, Lorigan P, Larkin J, McArthur G, Atkinson V, et al. Efficacy and toxicity of treatment with the anti-CTLA-4 antibody ipilimumab in patients with metastatic melanoma after prior antiPD-1 therapy. Br J Cancer. 2016;114(10):1084-9.

101. Balagani A, Arain M, Sheshadri A. Bronchiolitis obliterans after combination immunotherapy with pembrolizumab and ipilimumab. J Immunother Precision Oncol. 2018;1(1):49-52.

102. Kolla BC, Patel MR. Recurrent pleural effusions and cardiac tamponade as possible manifestations of pseudoprogression associated with nivolumab therapy-a report of two cases. J Immunother Cancer. 2016;4:80.

103. Borghaei H, Paz-Ares L, Horn L, Spigel DR, Steins M, Ready NE, et al. Nivolumab versus docetaxel in advanced nonsquamous non-small-cell lung cancer. N Engl J Med. 2015;373(17):1627-39.

104. Berthod G, Lazor R, Letovanec I, Romano E, Noirez L, Mazza Stalder J, et al. Pulmonary sarcoid-like granulomatosis induced by ipilimumab. J Clin Oncol. 2012;30(17):e156-9.

105. Bronstein Y, Ng CS, Hwu P, Hwu WJ. Radiologic manifestations of immune-related adverse events in patients with metastatic melanoma undergoing antiCTLA-4 antibody therapy. AJR Am J Roentgenol. 2011;197(6):W992-w1000.

106. Reuss JE, Kunk PR, Stowman AM, Gru AA, Slingluff CL Jr, Gaughan EM. Sarcoidosis in the setting of combination ipilimumab and nivolumab immunotherapy: a case report $\&$ review of the literature. J Immunother Cancer. 2016;4:94.

107. Tetzlaff MT, Nelson KC, Diab A, Staerkel GA, Nagarajan P, Torres-Cabala CA, et al. Granulomatous/sarcoid-like lesions associated with checkpoint inhibitors: a marker of therapy response in a subset of melanoma patients. J Immunother Cancer. 2018;6(1):14.

108. Ramstein J, Broos CE, Simpson LJ, Ansel KM, Sun SA, Ho ME, et al. IFN-gamma-producing T-helper 17.1 cells are increased in sarcoidosis and are more prevalent than T-helper type 1 cells. Am J Respir Crit Care Med. 2016;193(11):1281-91.

109. Facco M, Cabrelle A, Teramo A, Olivieri V, Gnoato M, Teolato S, et al. Sarcoidosis is a Th1/ Th17 multisystem disorder. Thorax. 2011;66(2):144-50.

110. von Euw E, Chodon T, Attar N, Jalil J, Koya RC, Comin-Anduix B, et al. CTLA4 blockade increases Th17 cells in patients with metastatic melanoma. J Transl Med. 2009; 7:35.

111. Attia P, Phan GQ, Maker AV, Robinson MR, Quezado MM, Yang JC, et al. Autoimmunity correlates with tumor regression in patients with metastatic melanoma treated with anticytotoxic T-lymphocyte antigen-4. J Clin Oncol. 2005;23(25):6043-53. 
112. Horvat TZ, Adel NG, Dang TO, Momtaz P, Postow MA, Callahan MK, et al. Immune-related adverse events, need for systemic immunosuppression, and effects on survival and time to treatment failure in patients with melanoma treated with ipilimumab at Memorial Sloan Kettering Cancer Center. J Clin Oncol. 2015;33(28):3193.

113. Santini FC, Rizvi H, Wilkins O, van Voorthuysen M, Panora E, Halpenny D, et al. Safety of retreatment with immunotherapy after immune-related toxicity in patients with lung cancers treated with antiPD(L)-1 therapy. J Clin Oncol. 2017;35:9012.

114. Pollack MH, Betof A, Dearden H, Rapazzo K, Valentine I, Brohl AS, et al. Safety of resuming anti-PD-1 in patients with immune-related adverse events (irAEs) during combined anti- CTLA-4 and anti-PD1 in metastatic melanoma. Ann Oncol. 2018;29(1):250-5.

115. Puzanov I, Diab A, Abdallah K, Bingham CO 3rd, Brogdon C, Dadu R, et al. Managing toxicities associated with immune checkpoint inhibitors: consensus recommendations from the Society for Immunotherapy of Cancer (SITC) Toxicity Management Working Group. J Immunother Cancer. 2017;5(1):95.

116. Cunliffe A, Armato SG 3rd, Castillo R, Pham N, Guerrero T, Al-Hallaq HA. Lung texture in serial thoracic computed tomography scans: correlation of radiomics-based features with radiation therapy dose and radiation pneumonitis development. Int J Radiat Oncol Biol Phys. 2015;91(5):1048-56.

117. Colen RR, Fujii T, Bilen MA, Kotrotsou A, Abrol S, Hess KR, et al. Radiomics to predict immunotherapyinduced pneumonitis: proof of concept. Investig New Drugs. 2018;36(4):601-7.

118. Abraham $\mathrm{C}$, Cho J. Interleukin-23/Th17 pathways and inflammatory bowel disease. Inflamm Bowel Dis. 2009;15(7):1090-100.

119. Tarhini AA, Zahoor H, Lin Y, Malhotra U, Sander C, Butterfield LH, et al. Baseline circulating IL-17 predicts toxicity while TGF-beta1 and IL-10 are prognostic of relapse in ipilimumab neoadjuvant therapy of melanoma. J Immunother Cancer. 2015;3:39.

120. Kim S, Shannon V, Sheshadri A, Kantarjian HM, Garcia-Manero G, Im J, et al. Th1/Th17 hybrid CD4+ cells in bronchial alveolar lavage fluid from leukemia patients with checkpoint inhibitor-induced pneumonitis. J Clin Oncol. 2017;36(5 suppl):204.

121. Antonia SJ, Villegas A, Daniel D, Vicente D, Murakami S, Hui R, et al. Durvalumab after chemoradiotherapy in stage III non-small-cell lung cancer. N Engl J Med. 2017;377(20):1919-29.

122. Cardinal-Fernandez P, Lorente JA, Ballen-Barragan A, Matute-Bello G. Acute respiratory distress syndrome and diffuse alveolar damage. New insights on a complex relationship. Ann Am Thorac Soc. 2017;14(6):844-50.

123. El Majzoub I, Qdaisat A, Thein KZ, Win MA, Han MM, Jacobson K, et al. Adverse effects of immune checkpoint therapy in cancer patients visiting the emergency Department of a Comprehensive Cancer Center. Ann Emerg Med. 2019;73(1):79-87.

124. Ferguson ND, Fan E, Camporota L, Antonelli M, Anzueto A, Beale R, et al. The Berlin definition of ARDS: an expanded rationale, justification, and supplementary material. Intensive Care Med. 2012;38(10):1573-82.

125. Force ADT, Ranieri VM, Rubenfeld GD, Thompson BT, Ferguson ND, Caldwell E, et al. Acute respiratory distress syndrome: the Berlin definition. JAMA. 2012;307(23):2526-33.

126. Guerin C, Bayle F, Leray V, Debord S, Stoian A, Yonis $\mathrm{H}$, et al. Open lung biopsy in nonresolving ARDS frequently identifies diffuse alveolar damage regardless of the severity stage and may have implications for patient management. Intensive Care Med. 2015;41(2):222-30.

127. Pillai RN, Behera M, Owonikoko TK, Kamphorst AO, Pakkala S, Belani CP, et al. Comparison of the toxicity profile of PD-1 versus PD-L1 inhibitors in non-small cell lung cancer: a systematic analysis of the literature. Cancer. 2018;124(2):271-7.

128. Stroud CR, Hegde A, Cherry C, Naqash AR, Sharma N, Addepalli S, et al. Tocilizumab for the management of immune mediated adverse events secondary to PD-1 blockade. J Oncol Pharm Pract. 2019;25(3):551-7.

129. Suresh K, Psoter KJ, Voong KR, Shankar B, Forde PM, Ettinger DS, et al. Impact of checkpoint inhibitor pneumonitis on survival in NSCLC patients receiving immune checkpoint immunotherapy. J Thorac Oncol. 2019;14(3):494-502.

130. Suresh K, Voong KR, Shankar B, Forde PM, Ettinger DS, Marrone KA, et al. Pneumonitis in non-small cell lung cancer patients receiving immune checkpoint immunotherapy: incidence and risk factors. J Thorac Oncol. 2018;13(12):1930-9.

131. Kelly K, Infante JR, Taylor MH, Patel MR, Wong DJ, Iannotti N, et al. Safety profile of avelumab in patients with advanced solid tumors: a pooled analysis of data from the phase 1 JAVELIN solid tumor and phase 2 JAVELIN Merkel 200 clinical trials. Cancer. 2018;124(9):2010-7.

132. Brahmer JR, Lacchetti C, Schneider BJ, Atkins $\mathrm{MB}$, Brassil KJ, Caterino JM, et al. Management of immune-related adverse events in patients treated with immune checkpoint inhibitor therapy: American Society of Clinical Oncology Clinical Practice Guideline. J Clin Oncol. 2018;36(17):1714-68.

133. Haanen J, Carbonnel F, Robert C, Kerr KM, Peters $\mathrm{S}$, Larkin J, et al. Management of toxicities from immunotherapy: ESMO Clinical Practice Guidelines for diagnosis, treatment and follow-up. Ann Oncol. 2017;28(suppl_4):iv119-iv42.

134. National Comprehensive Cancer Network. Management of immunotherapy-related toxicities (Version 1.2018). https://www.nccn.org/professionals/physician_gls/pdf/immunotherapy.pdf. Accessed 24 Apr 2019. 